\title{
Housing and Health
}

\section{Sanitation}

\author{
Stella Lowry
}

Sanitation has had, and continues to have, more impact on health than any advance in medical science. In developing countries over eight million children die from diarrhoeal illnesses each year because of poor sanitation, ' and in nineteenth century Britain epidemics of cholera and typhoid were common until the introduction of clean drinking water and safe sewage disposal. Now we take good sanitation for granted. Yet recent incidents, such as the contamination of water with aluminium in Camelford in 1988 and revelations that British water does not meet European Community standards, have posed questions about the safety of our domestic water supply and our handling of waste. People in Britain use, on average, 130 litres of water a day each. How are standards maintained, and where can the systems break down?

\section{Water quality}

Until last year the only requirement of drinking water in Britain was that it should be "wholesome." Various guidelines had been issued by government departments and the World Health Organisation, but the Secretary of State for the Environment was the final arbiter of what constituted wholesome water. In 1980 the European Community issued a directive (80/778/ London WC1H 9JR

Stella Lowry, MB, assistant

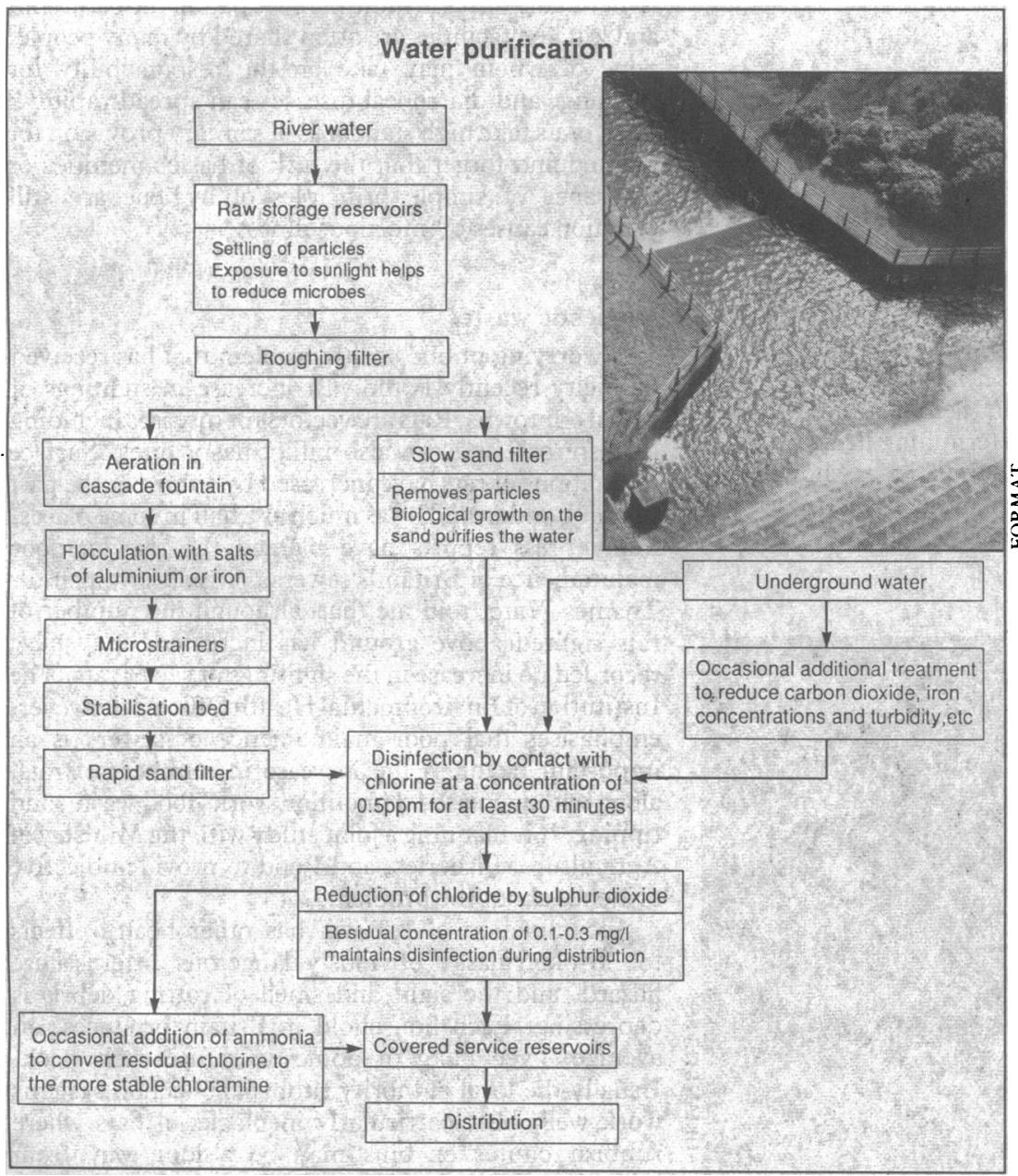

How water is purified
EEC) about drinking water quality; it came into force fully in 1985. The British government decided that water quality would meet the standards of the directive if the average results of tests did so. (In the year ending June 1989 the failure rate in quality tests was less than two per thousand.) The community decided, however, that each and every sample must comply; hence the recent publicity about Britain's failure to reach European standards.

The European Community directive lays down safe limits for a range of chemical and microbiological substances in water. Complying with these standards will cost about $£ 3.8$ billion up to the year 2000 , and the water industry thinks that the interpretation of the requirements is too harsh. Mr Alan Neald from Thames Water pointed out that the European limits are based on safe concentrations for lifetime exposure to various substances. He also told me that Britain is not the only country having difficulty in implementing the directive-only two member countries have not been threatened with disciplinary action by the community.

About $70 \%$ of Britain's drinking water comes from rivers and the rest from underground sources. The National Rivers Authority is responsible for the use of water resources and enforces pollution control based on standards determined by the uses to which the water is put. The quality of water sources depends largely on pollution control. Over $80 \%$ of sewage discharged into rivers or tidal waters is treated biochemically first. Water authorities spent over $£ 100 \mathrm{~m}$ in capital and operating costs in 1987 in collecting, treating, and disposing of sewage.

Figure 1 summarises the process of water purification, although new techniques using ozone or activated charcoal are being developed. River water is held in raw storage tanks before processing. Sedimentation and some early purification occur here, but the main advantage is that if sources become polluted the intake to the reservoirs can be closed until the contaminated water has passed. (This often happens for a few days in autumn if the concentration of nitrate in river water rises when rain leaches out fertilisers used on farms in the summer.)

After purification water is disinfected before distribution. The chlorination of drinking water is perhaps the single most important public health measure ever introduced. Most of the chlorine is removed before distribution, but a small amount is left to maintain disinfection during distribution.

\section{Maintaining standards}

Microbiological and chemical quality control tests are required at each stage of purification. ${ }^{3}$ The new water companies are also responsible for quality throughout the distribution system and for maintaining the pipework as far as the stopcock in houses. The quality control checks include random tests for the plumbing metals copper, lead, and zinc. In the past domestic plumbing has been identified as a source of lead in drinking water and the concentration has correlated with the blood concentration of lead in occupants. ${ }^{+}$Modern pipework is made of copper or plastic, but lead is still used in solders and there are 
many lead pipes left in Britain. In soft water regions like Scotland orthophosphate is often added to water to reduce its plumbosolvency. The current European standard for lead in drinking water is a maximum concentration of $50 \mu \mathrm{g} / \mathrm{l}$, and achieving this throughout Britain is one of the major obstacles to meeting the new directive.

Recent legislation has established an independent drinking water inspectorate to monitor quality, but the office is not yet up and running. Since the privatisation of the industry was announced the water companies have been inundated with queries from the public about the quality of drinking water and how it is controlled. Although the water companies are required to make the results of their quality control tests available to the public, the regulations are so complicated and the results of tests so technical that it is unlikely that many people will be able to make much sense of them.

Responsibility for water quality does not stop with the supplying company-local authorities also have a duty to "make themselves aware" of the quality of water in their areas. This vague requirement is open to interpretation, but, as Graham Jukes from the Institution of Environmental Health Officers told me, local authorities could be criticised in the event of an incident if they have relied on the statistics produced by the industry, and they may also face criticism for spending large amounts of money on their own tests. Environmental health officers have always been responsible for making quality checks on the private water companies; now they must also monitor the new ones, and they are already overworked. Over 400 more officers are needed in Britain-a shortage of about $8 \%$. With so much public concern, the lack of information that can be understood by the public, and recent "bad press" it is perhaps not surprising that there is now a growing trade in home water treatment systems, which are of dubious benefit.

\section{Access to basic amenities}

A national policy on water quality is all very well, but it is of little benefit to families who do not have access to basic sanitary provision. In 1986, 463000 houses in Britain still lacked one or more of the basic amenities of a kitchen sink, wash hand basin, shower or bath, and indoor toilet. In the private rented sector $8 \%$ of properties lacked at least one of these. ${ }^{5}$ Many people live in multiple occupier houses in which, although the amenities may exist, access to them is limited. Access to facilities is important in determining health: studies of people rehoused from slums have shown that standards of hygiene rise when clean water is freely available, even without specific educational programmes. ${ }^{6}$

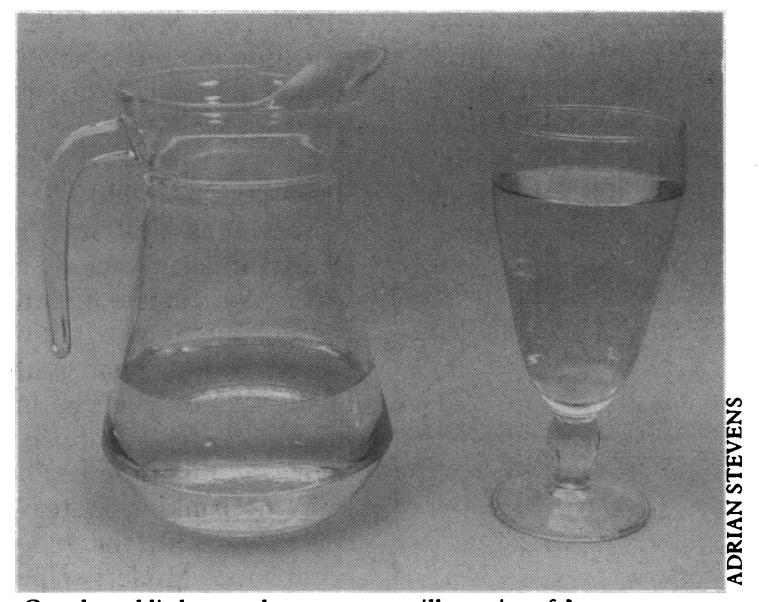

Can the public be sure that our water will remain safe?

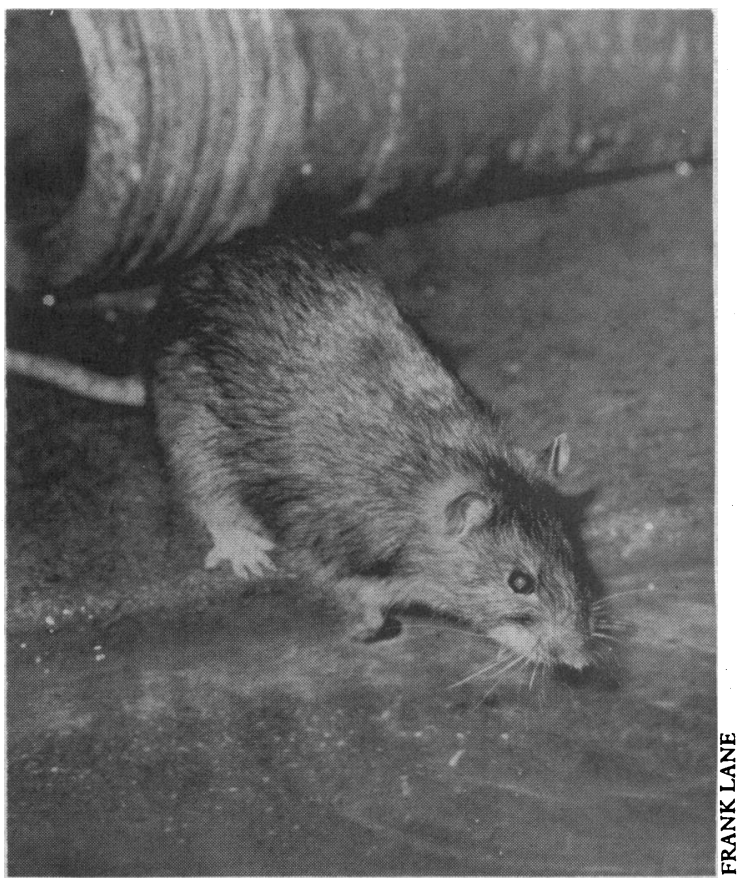

Rats are on the increase, but who is going to solve the problem?

Health can be put at risk if sanitary equipment is not properly maintained or used. Flushing a toilet creates splashes and aerosols, which have the potential of spreading infection. The flushing handle on a toilet and inner handles on bathroom doors are potential sources of infection, so it is better to have a wash hand basin in the same room as the toilet. These risks present little problem in most homes, where standards of hygiene are high and extra care can be taken if a family member is ill, but in houses in multiple occupation the bathroom and kitchen facilities are often shared by many people, none of whom may take on the responsibility for cleaning, and diarrhoeal diseases can spread rapidly. Most of us take high standards of sanitary provision for granted and forget that the lack of basic amenities or ignorance of simple principles of hygiene are still common causes of infectious illness.

\section{Domestic waste}

A worrying public health problem that has received publicity recently is the vast increase in sightings of rats in our towns. Rats are vectors for diseases including leptospirosis and can also inflict nasty bites. Surface infestations of rats have increased by a third in the past year in London and by as much as a half in some places. Many press reports have blamed the rise on poor maintainence of Britain's sewers. ${ }^{8}$ A spokeswoman for Thames Water told me that, although the number of rats sighted above ground has increased, they have recorded no increase in the sightings of sewer rats. The Institution of Environmental Health Officers, however, emphasises that poor maintainence of sewers is an important factor in the increase in numbers of rats, along with increased demolition work, food waste, and tipping. It is planning a joint study with the Ministry of Agriculture, Fisheries, and Food to provide objective evidence about the problem.

Accumulation of rubbish has other health effects too. Broken glass is obviously dangerous, litter is a fire hazard, and the sight and smell of rotting debris is depressing. Each household in Britain produces, on average, over $11 \mathrm{~kg}$ of domestic refuse each week. Usually the local authority rubbish collection systems work well, but, particularly in blocks of flats where rubbish chutes or bins may be a long way from individual front doors, the system can break down. 
When it does there are too few environmental health officers and too little local government funding to ensure that things are put right.

\section{Conclusions and comments}

Most people in Britain have access to high quality water supplies and waste and sewage disposal services. Some of our most vulnerable groups are, however, deprived of basic sanitary amenities or have only limited access to poorly maintained facilities. Poor hygiene is still a cause of infectious illness in Britain. Doctors still have a role in educating their patients about such matters and in campaigning for an end to the overcrowded, unsanitary conditions that many families endure.

Although we now have laws to protect the quality of our drinking water, the recent privatisation of the industry has led to public concern that standards may be sacrificed to profit. Independent information about quality should be not only available to the public but also made understandable to lay people. People's fears will not be easily allayed by an understaffed inspectorate, and environmental health officers are already overworked. Public confidence and public health require that this is corrected.

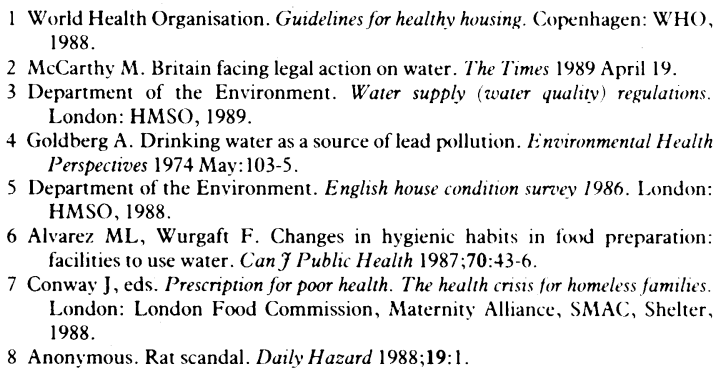
London: HMSO, 1989.

4 Goldberg A. Drinking water as a source of lead pollution. Environmental Health Perspectives 1974 May: 103-5.

Department of the Environment. English house condition survey 1986. London HMSO, 1988.

6 Alvarez ML, Wurgaft F. Changes in hygienic habits in food preparation facilities to use water. Can f Public Health 1987;70:43-6.

7 Conway J, eds. Prescription for poor health. The health crisis for homeless families London: London Food Commission, Maternity Alliance, SMAC, Shelter. 1988.

8 Anonymous. Rat scandal. Daily Hazard 1988;19:1

\title{
Letter from Bombay
}

\section{The humanities and medicine}

\author{
Sunil K Pandya
}

Most invitations to symposia elicit lukewarm responses. There is a sameness about medical meetings, most offering a few inspiring presentations amid many humdrum papers.

The symposium held some weeks ago in Bangalore made one sit up with alacrity. Entitled "Humanity and Medicine," it dealt with the humanities, devotion to human welfare, and a way of life centred on human values. The term humanity was interpreted as referring to the "quality of being humane." The humanities thus encompass all the branches of learning. The symposium aimed at studying how far we medical doctors practise humanity and seek proficiency in the humanities. The speakers included a philosopher (who also edits a cultural journal), an authority of ayurveda, a senior scientist now specialising in public health in our villages, a senior civil servant, a journalist, a physiologist (keenly interested in Indian sculpture), psychologists, psychiatrists, and other neuroscientists

The titles of the papers included "Culture and its relevance in health"; "Changing patterns in menta health care-disappearing humanism and cultural heritage"; "Traditional beliefs in emerging health care" (emhasising the need to pay attention to traditional beliefs and use them to reinforce our own advice); "Literature and medicine"; "Role of art and music in health"; "Art, sculpture, and medicine"; "The medical dilemma: health care or health business" (focusing on the rampant commercialism in Indian medicine); "Humanisation of hospital services" (analysing the experiences of inpatients and suggesting means of improvement); "Human values, social justice, ethics, and health"; "Ethics and decision making, policy development" (dealing with decisions made by planning commissions, ministries of health, etc); "Approaches to involving patients in decision making"; "Holistic approach in medical practice"; and "Spiritual dimensions of health."

A study of ancient ayurvedic texts yields sound advice on the way in which the doctor should approach and treat his patient. The physician is commanded to keep the eternal values in mind all along and to base his practice on dharma (that which sustains all human beings). Promotion of health - not just freedom from disease-was to be the goal of the medical profession.
Modern Indian medicine is, alas, far removed from these ideals. A return to those hallowed values is essential if we are to improve our care of those who entrust themselves to us. We need to amalgamate our ancient wisdom with the best of modern medicine and pass this on to our students. Example being more effective than precept, we shall have to alter our own practice to start with.

\section{No justification for superiority}

We also need to listen to our patients, their relatives, and others trying to help the sick. There is much to learn from them. Many of us practising modern medicine are, at times, prone to dismiss everything not matching our concepts or notions. In the process we may be losing much needed wisdom gathered from centuries of experience, empirical or otherwise. There is no justification for the feeling of superiority we experience and tactlessly display to our patients and their near ones.

In part, our dehumanisation follows the quest for filthy lucre. In this process we spend most of our waking hours in collecting and hoarding more and more of what may be fairly described as mere material goods. Nourishment of the intellect and spirit suffers. We lose our inborn love for all that is truly beautifulthe wonders of nature, the joy of seeing a face light up in a smile, a literary masterpiece, an outstanding painting or sculpture, a dialogue between great minds.

To reverse the process in the present general milieu is not easy. It is not uncommon to find doctors exclaim, "Why do you expect medical men to behave differently from the rest of the populace?" We need to remind ourselves that we are and have been especially privileged. In a mass of illiterates and the poor we are highly educated and live comfortably. We have inherited the noble traditions. It ill becomes us to turn our backs on these facts and follow ignoble examples.

As you will note there was much of interest. Those wishing to learn more about the proceedings should contact Professor G N N Reddy, National Institute of Mental Health and Neurological Sciences, Hosur Road, Bangalore, 560029, Karnataka, India. 